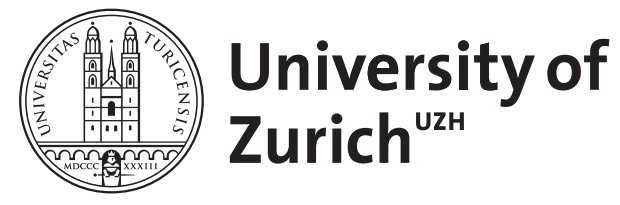

\title{
Adult Neurogenesis in Mammals: Variations and Confusions
}

Lipp, Hans-Peter ; Bonfanti, Luca

DOI: https://doi.org/10.1159/000446905

Posted at the Zurich Open Repository and Archive, University of Zurich

ZORA URL: https://doi.org/10.5167/uzh-125750

Journal Article

Published Version

Originally published at:

Lipp, Hans-Peter; Bonfanti, Luca (2016). Adult Neurogenesis in Mammals: Variations and Confusions. Brain, Behavior and Evolution, 87(3):205-221.

DOI: https://doi.org/10.1159/000446905 


\title{
Adult Neurogenesis in Mammals: Variations and Confusions
}

\author{
Hans-Peter Lipp ${ }^{\mathrm{a}-\mathrm{c}}$ Luca Bonfantid, e

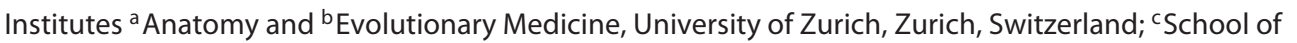 \\ Laboratory Medicine, University of Kwazulu-Natal, Durban, South Africa; ${ }^{\mathrm{d}}$ Department of Veterinary Sciences,

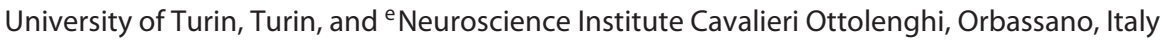

\section{Key Words}

Adult mammalian neurogenesis · Species differences · Adult hippocampal neurogenesis · Subventricular zone · Brain evolution · Brain structural plasticity · Doublecortin · Cell proliferation

\begin{abstract}
Mammalian adult neurogenesis has remained enigmatic. Two lines of research have emerged. One focuses on a potential repair mechanism in the human brain. The other aims at elucidating its functional role in the hippocampal formation, chiefly in cognitive processes; however, thus far it has been unsuccessful. Here, we try to recognize the sources of errors and conceptual confusion in comparative studies and neurobehavioral approaches with a focus on mice. Evolutionarily, mammalian adult neurogenesis appears as protracted juvenile neurogenesis originating from precursor cells in the secondary proliferation zones, from where newly formed cells migrate to target regions in the forebrain. This late developmental process is downregulated differentially in various brain structures depending on species and age. Adult neurogenesis declines substantially during early adulthood and persists at low levels into senescence. Short-lasting episodes in proliferation or reduction of adult neurogenesis may reflect a multitude of factors, and have been studied chiefly in mice and rats. Comparative studies face both
\end{abstract}

species-specific variations in staining and technical abilities of laboratories, lacking quantification of important reference measures (e.g. granule cell number) and evaluation of maturational markers whose persistence might be functionally more relevant than proliferation rates. Likewise, the confusion about the functional role of variations in adult hippocampal neurogenesis has many causes. Prominent is an inferential statistical approach, usually with low statistical power. Interpretation is complicated by multiple theories about hippocampal function, often unrealistically extrapolating from humans to rodents. We believe that the field of mammalian adult neurogenesis needs more critical thinking, more sophisticated hypotheses, better statistical, technical and behavioral approaches, and a broader conceptual perspective incorporating comparative aspects rather than neglecting them.

๑ 2016 S. Karger AG, Basel

\section{Introduction}

After decades of intensive research, mammalian adult neurogenesis has remained enigmatic. The initial protagonists and early followers are still unsure about the functional meaning of adult neurogenesis in general [Bonfanti, 2016] and adult hippocampal neurogenesis (AHN) in particular, although they rarely question its functional

\section{KARGER}

E-Mail karger@karger.com

www.karger.com/bbe
(C) 2016 S. Karger AG, Basel

0006-8977/16/0873-0205\$39.50/0
Hans-Peter Lipp, $\mathrm{PhD}$

Institute of Anatomy, University of Zurich

Winterthurerstrasse 190

$\mathrm{CH}-8057$ Zurich (Switzerland)

E-Mail hplipp@anatom.uzh.ch 


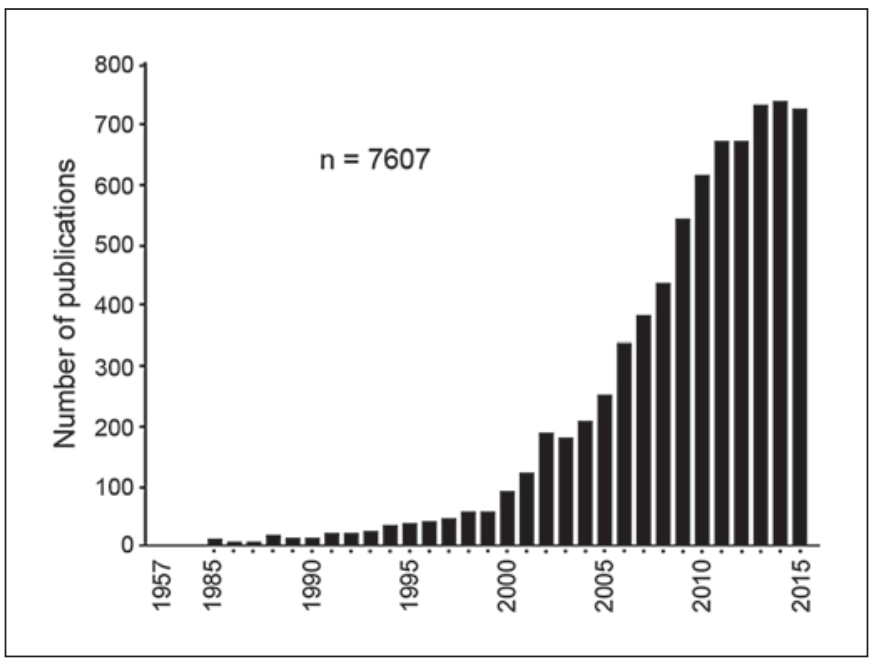

Fig. 1. Exponential increase of scientific publications in the field of adult neurogenesis during the last three decades (source: PubMed).

significance. A count of publications related to adult neurogenesis reveals a rapid increase from the year 2000 to 2015, the last 4 years revealing between 600 and 700 papers per year (fig. 1). The obvious benefit of the research is better insight into molecular mechanisms underlying development and differentiation of neurons and stem cells in the neurogenic zones of the mammalian brain. On the other hand, a research field in which some 7,500 publications have appeared without elucidating the functional meaning of adult neurogenesis requires consideration about what might have gone wrong.

Clearly, two main lines of research have emerged across the years. One focuses on adult neurogenesis as a potential repair mechanism in the human brain, investigating molecular mechanisms controlling it or at least mediating proliferation, cell fate, and survival of newly generated neurons, with emphasis on potential applications for brain repair [Martino et al., 2011; Lindvall and Kokaia, 2015; Alunni and Bally-Cuif, 2016]. This approach, which also includes comparative studies, is more fact-related, and emerging contradictions and conclusions can be reconciled. Nonetheless, one must still await better understanding and more studies to judge whether adult neurogenesis provides a substantial potential for brain repair or whether it is just leading to a (protracted) developmental end point imposed by structural rules of the mammalian brain, including evolutionary constraints and nerve tissue reactions [Weil et al., 2008; Bonfanti, 2011; Peretto and Bonfanti, 2014; Bonfanti, 2016].
The other research line emerged separately and tries to elucidate the functional role of adult neurogenesis, chiefly in cognitive processes related to hippocampal function, often referred to as AHN. Contradictory data and lack of replication are the main problems of this line or subfield, as evidenced by two text passages from papers conveying the same message in the title. One is a classic paper by Gould et al. [1999] entitled 'Learning enhances adult neurogenesis in the hippocampal formation'. Some 14 years later, Epp et al. [2013] published a paper 'Hippocampusdependent learning influences hippocampal neurogenesis' and the abstract explains: 'One particular area of research has examined the effects of hippocampus dependent learning on proliferation, survival, integration and activation of immature neurons in response to memory retrieval. Within this subfield there remains a range of data showing that hippocampus dependent learning may increase, decrease or alternatively may not alter these components of neurogenesis in the hippocampus'. Such statements do not facilitate interpretation of the findings in this field, even though the latter paper provides a useful listing of factors that might account for different results, notably in one subfield of AHN only.

Evidently, the problem with studies in adult neurogenesis is not the lack of results, but that there are too many findings with inconclusive and seemingly irreproducible results, specifically when behavioral changes are involved. Yet reproducibility is a cornerstone of good science [Morrison, 2014]. Since a detailed review of many thousand studies with conflicting or doubtful data would go beyond the space limits of this article, we aim at readers with limited experience in the field of adult neurogenesis and try to identify the sources of variation precluding a clear picture in the field. First, we will give a framework based on comparative evaluation of adult neurogenesis in different mammalian species, highlighting that ecological adaptations ultimately determine patterning and functionality of adult neurogenesis [Peretto and Bonfanti, 2014]. The second goal is to provide the nonexperts in the field with a set of criteria by which studies about the functionality of AHN can be weighted according to whether they ignored or respected known sources of methodological confounds or comparative aspects. To this end, we shall discuss selected high-impact papers and draw attention to their hidden methodological problems. For neurobehavioral studies with laboratory rodents aimed at identifying relations between $\mathrm{AHN}$ and behavior, we identify factors known to produce confounds in cell counts, but also confounds in behavioral testing that may blur relations between AHN and behavior. Finally, we will use 
published examples to show why the standard presentation of data in this field is masking important information. We emphasize that the term 'field' does not only denote the leading laboratories, but encompasses the many follow-up studies employing (often uncritically) methods and terminology of the main players.

\section{Findings from Comparative Research}

\section{Adult Neurogenesis Is Highly Heterogeneous in \\ Vertebrates, Even among Mammals}

Adult mammalian neurogenesis follows essentially the same rules as embryonic brain development: in early development, neuronal and glial precursor cells are generated in the periventricular germinal layers from where they migrate towards the external surface of the brain along radial guidelines formed by special glial cells [Bonfanti and Peretto, 2007; Kriegstein and Alvarez-Buylla, 2009]. Two regions remote from the ventricles contain secondary proliferation zones in which neural precursor cells continue to divide: the dentate gyrus and, temporarily, the superficial layers of the cerebellum. In the adult mammalian brain, however, regular proliferation of new cells became restricted evolutionarily to two zones harboring stem cells and coined 'canonical' by Feliciano et al. [2015], namely the forebrain subventricular zone (SVZ; giving rise to a stream of inhibitory neurons for the olfactory bulb), and the subgranular zone (SGZ) of the granule cell layer in the dentate gyrus. In addition, there are a number of brain sites in which adult neurogenesis can be sporadically observed, depending on species, age, and physiological and pathological status, the ensemble coined 'parenchymal' (non-canonical) and 'lesion-induced' neurogenic sites, respectively [Feliciano et al., 2015]. Unsurprisingly, their irregular nature is fueling controversies in the field of neuroregenerative approaches since virtually all these noncanonical neurogenic processes do not produce neuronal functional integration, thus remaining 'incomplete' [Bonfanti and Peretto, 2011].

From a comparative point of view, mammals do not show true adult neurogenesis as found in bird species with seasonal variation in behavior-controlling brain structures [Nottebohm, 2004]. Rather, adult neurogenesis appears as protracted juvenile neurogenesis that is downregulated differentially in various brain structures depending on species and age levels. Adult neurogenesis in the SVZ-olfactory bulb system and AHN can be found in most mammalian species, but its expression is highly

Adult Neurogenesis in Mammals:

Variations and Confusions variable [Amrein et al., 2011; Bonfanti and Peretto, 2011; Amrein, 2015]. Species with the lowest level of expression are humans [Sanai et al., 2011], nonhuman primates [Kornack and Rakic, 1999; Jabes et al., 2010], many bat species including both Microchiroptera and Megachiroptera [Amrein et al., 2007], and cetaceans [Parolisi et al., 2015; Patzke et al., 2015], while shrews can switch off AHN completely after the first hibernation [Bartkowska et al., 2008; Amrein, unpublished data]. Likewise, the proliferation levels are low in long-living subterranean mole species [van Dijk et al., 2016a]. Levels of AHN appear high in some rodents showing a daily turnover rate of up to $1.5 \%$ of adult dentate granule cells, counterbalanced by increased apoptosis [Amrein et al., 2004], as contrasted to humans with an estimated level of $0.004 \%$ at 40 years [Spalding et al., 2013].

\section{Variable Expression of Markers for Juvenile Neurons}

In most species, adult neurogenesis is followed by developmental stages of the newly born neurons characterized by the expression of so-called 'juvenile proteins' thought to underlie functional plasticity. These include, among others, doublecortin (DCX), polysialylated neural cell adhesion molecule (PSA-NCAM; a low adhesive cell adhesion molecule involved in structural plasticity; see references in Bonfanti and Nacher [2012]), the transcription factor NeuroD, and others [Knoth et al., 2010]. DCX labeling is often used as a proxy for identification of newly generated neuroblasts since it is expressed transiently during the neurogenesis and migration process [Brown et al., 2003]. However, it cannot be used as the sole marker for newborn neurons. There are several studies showing that DCX staining can be observed in non-newly generated cells [Gomez-Climent et al., 2008; Luzzati et al., 2009; Klempin et al., 2011], such as the so-called 'immature' neurons of the cortical layer II (fig. 2b) [reviewed in Bonfanti and Nacher, 2012]. Thus, markers for juvenile neurons are, per se, not markers of neurogenesis but might be associated more broadly with structural plasticity [Bonfanti and Nacher, 2012]. Hence, observing high numbers of DCX-stained neurons in a dentate gyrus indicates both some degree of proliferation as well as functional plasticity. Likewise, NeuroD is interesting as it is activated during neuronal differentiation, specifically regulating mossy fiber synapses [Wilke et al., 2012], but also responds to neuronal activation similarly as other activity markers such as c-fos [Konishi et al., 2001]. To compare species meaningfully, the minimal requirements for obtaining a comprehensive view is counting the number of both Ki67+ and DCX+ cells, possibly also NeuroD+ or 


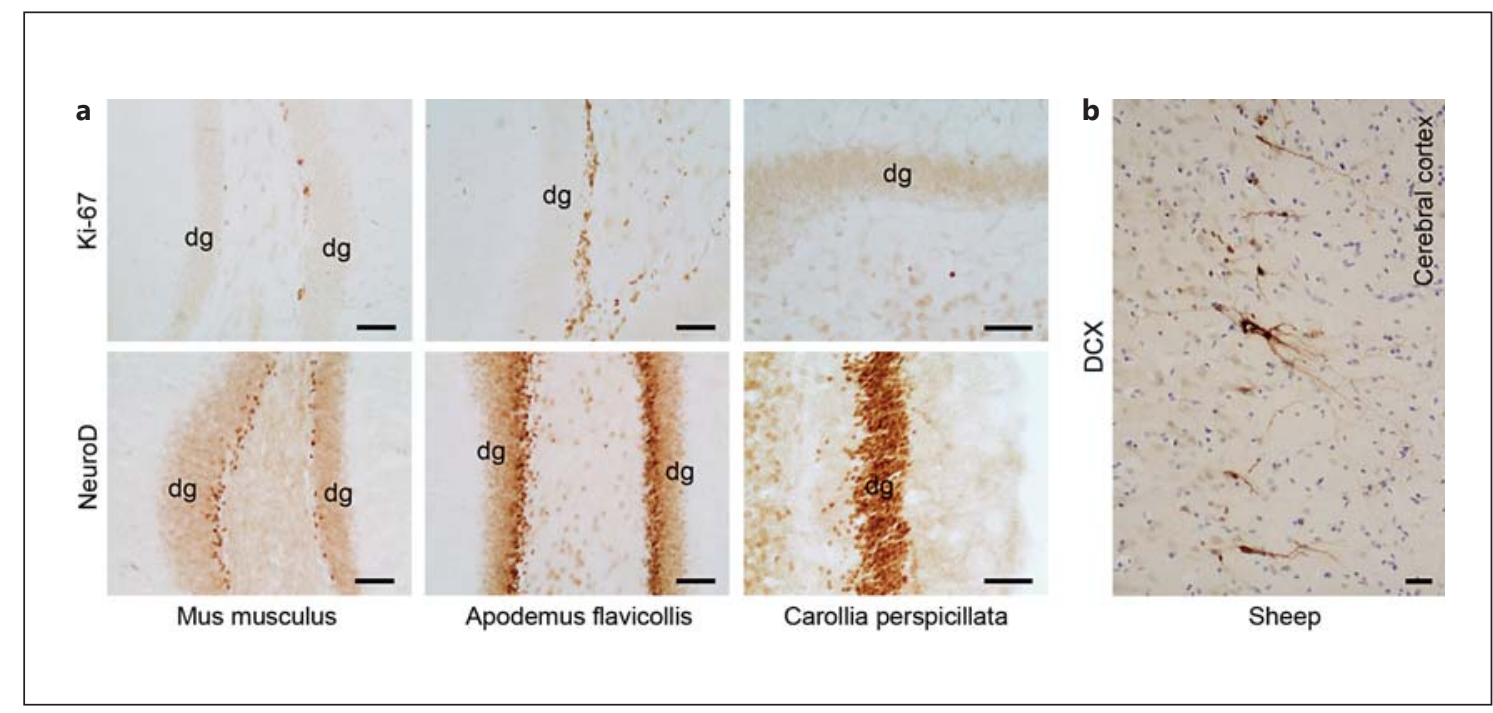

Fig. 2. a Species differences in the relation between proliferation marker (Ki-67) and plasticity marker indicating functionally juvenile neurons (NeuroD). Adult house mice (Mus musculus) can have a daily proliferation of about 3,000 new neurons, and adult wood mice (Apodemus flavicollis) show up to 15,000 new cells per day, but adult fruit-eating bats (Carollia perspicillata, captivity bred) show no visible proliferation. The plasticity marker NeuroD reveals a moderate number of presumably juvenile neurons in the

PSA-NCAM+ cells, and finally counting the total number of granule cells to have a reference frame.

Generally, in AHN the numbers of cells carrying proliferation markers and those staining for DCX correlate well. For example, in red foxes Amrein and Slomianka [2010] report a correlation coefficient of $r=0.80(n=7)$, while the correlation coefficient in mice as shown by Ben Abdallah et al. [2010] is $\mathrm{r}=0.98$ (correlated means of 6 age classes).

\section{Focus on Cell Numbers or Plasticity Features?}

On the other hand, the ratio between DCX+ cells and cells with proliferation markers can be extremely different across species. In the mice above, there were on average about 4 times more DCX+ cells than Ki67+ cells, but about 70 times more DCX+ cells than Ki-67+ cells were observed in the red foxes, which, in turn, showed 15 times more DCX+ cells than elderly beagle dogs [Siwak-Tapp et al., 2007]. In old naked mole rats, residual PSA-NCAM immunoreactivity was observed many years after the disappearance of any proliferation activity. Similar observations were made in the human dentate gyrus in which DCX+ cells were found long after detectable proliferation [Knoth et al., 2010]. Observing mouse and more stained neurons in the wood mouse, while in the bat virtually every granule cell expresses the marker protein. $\mathrm{dg}=$ Granule cell layer. Bat data from Amrein et al. [2007]; mouse and wood mouse sections from unpublished material (Amrein and Lipp). $\mathbf{b}$ The marker DCX is also expressed in neuronal populations, which are non-newly generated, such as the immature neurons of the cortical layer II (sheep; Piumatti, Palazzo and Bonfanti, unpublished data). Scale bars: $40 \mu \mathrm{m}$.

such temporal dissociation between neurogenesis and persistence of developmental markers raises fundamental questions.

A comparative view suggests a dual strategy to achieve neuronal plasticity: short living species such as mice or rats use a strategy of producing new cells providing the required plasticity levels, while long-living species develop mechanisms to preserve juvenile properties of developmentally generated granule cells or may reactivate molecular switches, generating cellular plasticity in adult neurons. This might be necessary to cope with the increasing age-dependent restrictions on proliferation and migration of newly formed neurons (see below). Indeed, the study by Penz et al. [2015] showed that juvenile features such as excitability of granule cells from newborn naked mole rats were conserved throughout life and without accompanying neurogenesis; the findings were interpreted as an example of neoteny (the conservation of early developmental features). Similar neotenic mechanisms might operate in bats, although de novo generation of juvenile proteins facilitating synaptic plasticity might reflect another strategy to maintain an optimal status for hippocampal activity for 20 years and more. 


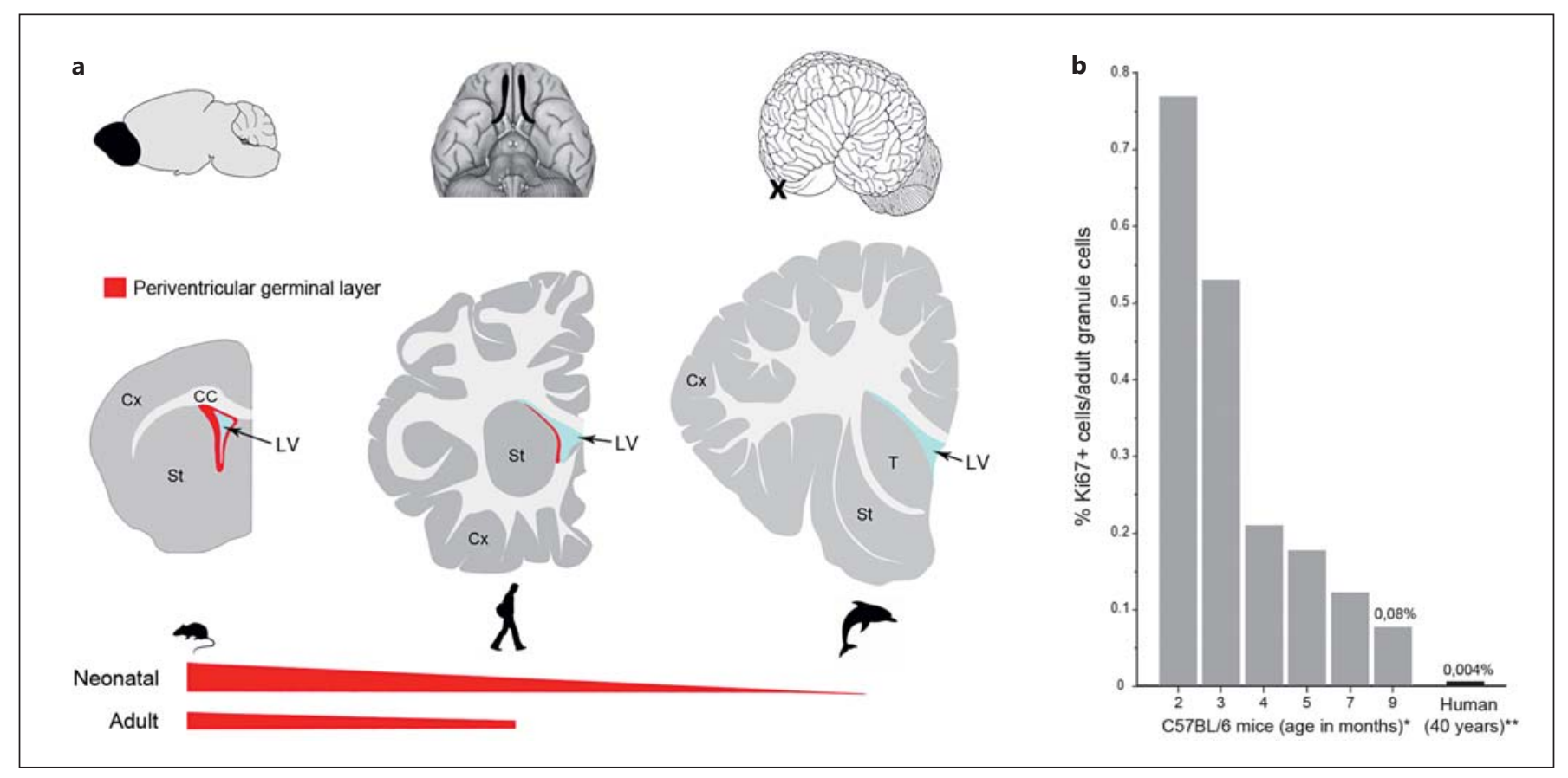

Fig. 3. Substantial decline of neurogenic activity in mammals of different species and ages, and reliability of markers in studying adult neurogenesis. a The SVZ germinative layer (red) is highly reduced in large-brained mammals already at birth; further reduction occurs with increasing ages. Such decline with respect to rodents appears to be related to the importance of olfaction/olfactory structures (top, black), far less prominent in humans and absent in dolphins (modified from Parolisi et al. [2015]). b Sub-

\section{Substantial Decline in Adult Neurogenesis Occurs}

Depending on Age, Mostly in Large-Brained

Mammals

A general finding among mammals is that adult neurogenesis in both the SVZ and SGZ declines substantially during early adulthood and persists at low levels. In the SVZ of large-brained animals, it partially disappears at very young ages [Paredes et al., 2016]. For example, the rostral migratory stream of neuroblasts generated in the SVZ and directed to the olfactory bulb in most mammals is virtually absent in humans reaching 2 years of age [Sanai et al., 2011], and no periventricular germinal layer is detectable in neonatal dolphins [Parolisi et al., 2015] (fig. 3a). Such reduction is likely due to a weak sense of olfaction in humans, especially relative to a rodent, and its absence in aquatic mammals like dolphins [Parolisi and Bonfanti, in preparation].

Thus far, a common pattern in the rodent SGZ is an exponential decline from juvenile levels early in life to low levels in adulthood, tapering off with progressing age

Adult Neurogenesis in Mammals:

Variations and Confusions stantial reduction of neurogenic activity also occurs in the hippocampus. Percentage of Ki67+ cells as related to the total granule cell number in C57BL/6 mice at different age levels (columns 2-9, in grey). The percentage roughly corresponds to daily turnover. * Replotted after Ben Abdallah et al. [2010]. Last column (black), the estimated percentage in human hippocampi as indicated incorrectly by Spalding et al. [2013] and Bergmann et al. [2015] (**) to be equivalent in mice and men.

[Amrein et al., 2011; Lazic, 2012b; Couillard-Despres, 2013], with the duration of this phase showing a moderate correlation with lifespan [Lazic, 2012b]. Such a timecourse may reflect the need to suppress rapidly uncontrollable juvenile neuronal excitability of dentate granule cells, while later episodes of short-lasting variations in proliferation during the tapering-off phase reflect a multitude of intervening factors of different origins and debated significance. Alternatively, as suggested by Couillard-Despres et al. [2011] newly born neurons may have different effects during various lifetime stages.

Detailed quantitative comparative evidence for the change in turnover rates is scarce since it requires (as in other comparative studies) both the counting of granule cell number as a reference, and counting cells with proliferation and maturation markers to obtain an age-dependent estimate of turnover rates in AHN. Thus far, this has been realized systematically in mice up to 9 months of age [Ben Abdallah et al., 2010], and to a lesser extent in macaque monkeys because of the low number of animals 
available [Jabes et al., 2010]. Jabes et al. reported in their four adult monkeys an estimated daily turnover rate of $0.02 \%$ in relation to the actual adult granule cells. A daily turnover rate in adult monkeys has been estimated (on the basis of BrdU injections and granule cell counts from the literature) as $0.004 \%$ [Kornack and Rakic, 1999]. Given the long lifespan of monkeys, this might allow for a lifetime replacement of neurons between 40 and 100\%.

\section{Quantifying AHN in Humans versus Mice: Problems and Real Errors}

Conceptually, the question whether AHN declines exponentially or is an age-related process is important. If the decline of AHN reflected biological ageing comparable to the loss of elasticity in arteries, ongoing neurogenesis would represent a process preventing age-related loss of function in the dentate gyrus. However, rapid downregulation of proliferation means that the level of persisting AHN must be kept low for physiological reasons, or may simply reflect the end of a developmental growth program that is not totally repressive as observed in many other parts of the body (e.g. in wisdom teeth or skull bones). The scientific problem is then to recognize whether variations of low levels of AHN during ageing are functionally relevant or not, and to understand the reasons for an exponential decline from childhood to adulthood.

In humans, systematic morphological postmortem studies about the lifetime course of newly added dentate granule cells are lacking. To obtain comparatively meaningful data, one should know the actual number of mature granule cells at a given time point. However, human granule cell numbers must be estimated from a few studies including different age classes, which revealed a huge individual variability between 10 and 30 million granule cells [West, 1993; Simic et al., 1997].

Knoth et al. [2010] studied the occurrence of numerous proliferation and maturation markers during human lifespan up to 100 years, interpreting their data carefully without attempts to determine turnover rates. By using DCX as a proxy for proliferation, they confirmed the exponential decrease model, reporting observation of Ki67+ cells up to the age of 38 years, and MCM2+ cells (a proliferation marker with a larger temporal window) up to 64 years, while DCX-positive cells were found up to old ages. NeuroD+ neurons disappeared after 10 years of age. Another study in humans reported few Ki67+ cells in aged hippocampi, observing substantial individual variation [Reif et al., 2006].

On the other hand, an often-cited study [Spalding et al., 2013] has claimed that the early decay of AHN in hu- mans is less severe, and that human $\mathrm{AHN}$ at 40 years is comparable with the C57BL/6 laboratory mouse (one of the most investigated strains) at 9-12 months, thus justifying translational studies in mice to explain functional changes in the adult and aging human hippocampus. These conclusions were derived from applying a well-established technique to study turnover in slowly reproducing tissue such as in the dentate gyrus, namely the incorporation of radioactive ${ }^{14} \mathrm{C}$ left from nuclear explosions in the 1950s.

Surprisingly, one of the chief (and often cited) conclusions of the CELL paper is wrong: the authors infer that daily turnover of new granule cells in humans at 40 years roughly corresponds to the turnover rate of 1-year-old mice as reported by Ben Abdallah et al. [2010]. The error became evident by checking a graph using the same data [Bergmann et al., 2015], depicting the proportions in mice and humans. Figure $3 \mathrm{~b}$ shows the true relation (humans: 700 new cells out of 20 million granule cells = $0.0035 \%$; mice at 9 months: 416 out of 0.5 million granule cells $=0.083 \%)$. Thus, men and mice appear to differ in turnover rates by a factor of 15-20 at roughly corresponding ages. We do not deny that the dynamics of granule cell proliferation in humans might be different from mice, but the conclusion that both species have comparable turnover rates at corresponding age levels is untenable by the available data.

\section{Other Lifetime Changes in the Dentate Gyrus}

Likewise, attention should be directed to local nonproliferative growth processes accompanying adult neurogenesis in the dentate gyrus as they may equally affect hippocampal processing. Indeed, in the SGZ and the dentate gyrus, other slow growth processes occur and have their own time course. For example, a lifetime study in 69 guinea pigs, spanning a period from 5 to 1,100 days, showed that the density of recurrent mossy fiber collaterals being associated with presumably inhibitory basket cells increased in two spurts: an early one before puberty, and a later one in midlife at 600 days; no additional proliferation was observed thereafter [Wolfer and Lipp, 1995]. Dentate neurogenesis had not been measured, but it is safe to assume that it was probably reduced in the old guinea pigs [Akers et al., 2014]. Similarly, a lifetime study in 47 hybrid mice $(\mathrm{F} 1 \mathrm{C} 57 \times \mathrm{DBA} / 2)$ using the Gallyas myelin stain revealed ongoing myelination in the SGZ from day 40 to day 640; in old mice it was more prominent in males than in females [Vich-Plesko, 1999]. Given the repressive effect of myelin components on axonal growth [Caroni and Schwab, 1993; Fawcett et al., 2012], 
one can thus expect in ageing mice an increasing blocking of neurite growth towards CA3, impairing the normal functional integration of mossy fibers and with unknown behavioral consequences. Unfortunately, any suspected parallelism of age-related changes in dendritic trees, synaptic arrangements, and other features of hippocampal morphology require lifetime studies that have become rare in a field driven by the need for rapid publications, with the laudable exception being the study on naked mole rats [Penz et al., 2015].

\section{AHN and Behavior}

\section{Biological and Behavioral Sources of Confounds}

Age

Perhaps the most neglected confound is the age of the tested animals. For example, most mice are tested at the approximate age of 2-3 months, even though it is now known that this period is characterized by an exponential decline of cell proliferation [Ben Abdallah et al., 2010; Gil-Mohapel et al., 2013]. The rapid decline of AHN has also been observed in rats, both in laboratory strains and wild-caught Norway rats [Epp et al., 2009]. The dynamics of the decline may depend on many factors, but if the age of controls and experimental animals is not determined with utmost care and fully comparable, unrecognized age differences may introduce substantial variability of findings. Specifically, manipulations thought to induce increased or decreased proliferation might simply have altered the time course of the decline, but without knowledge of the dynamics of AHN in the own animal sample it is not possible to define whether a treatment has increased or decreased proliferation rates or survival of newborn cells. To illustrate this point, the study by Ben Abdallah et al. [2010] was not planned. During an irradiation experiment aimed at reducing AHN, we noticed that the controls at the age of 3 months had significantly less newborn cells than those at 2 months - an unpleasant finding as it indicated unstable control values, and made it necessary to document the time course of the decline. In a positive vein, comparing adult mice or rats at the age of 2 and 3 months can easily test whether different levels of AHN predict hypothesized cognitive or emotional differences - at least a first approach does not require experimental manipulation [Gil-Mohapel et al., 2013]. Thus, we strongly recommend checking in any given paper the age of the animals used. Studies in which mice or rats had been tested at the age of at least 4 months or beyond are more likely to provide reliable results than com-

Adult Neurogenesis in Mammals:

Variations and Confusions parisons at earlier ages. There are recent examples considering this age confound [Nakashiba et al., 2012; van Dijk et al., 2016b]. We do realize that the exorbitant costs of animal husbandry are not in favor of keeping mice or rats for longer periods, but this should be taken into consideration when planning new studies.

On the other hand, the Frankland Group [Akers et al., 2014] has successfully exploited the dynamics of the early decline by asking what changes in memory can be observed in children with supposedly high levels of young granule cells. Children have natural deficits in long-term memory, predicting that high proliferation of granule cells might cause forgetting of acquired responses in adult mice. They carefully selected the time window for manipulating proliferation of granule cells, verified the agedependent decline in their mouse samples, avoided BrdU injections, and could show in genetically modified mice that memory stability (retention of conditioned fear responses) was impaired by increasing AHN through voluntary running, and improved by reducing chemically AHN. Likewise, blocking AHN at juvenile stages mitigated retention. Moreover, precociously born species such as degus or guinea pigs showed less infantile amnesia, but revealed memory impairment when neurogenesis was increased by means of wheel-running. Taken together, the data strongly suggest a role of adult neurogenesis in erasing established memories/behaviors in different species.

\section{Genetic Variation}

With a few exceptions, the genetic background of the animals studied appears to be of little relevance in many studies of behavioral correlates of AHN. The most frequently used strain, C57BL/6, has become a de facto, yet undeserved, gold standard in many fields including neurobehavioral studies. Its main advantage is relatively robust learning under different conditions and a high proliferation rate in the SGZ [van Dijk et al., 2016b]. On the other hand, C57BL/6 mice suffer, as every inbred mouse strain, from various subtle genetic mutations in homozygous states. Behavior genetic studies have shown that F1 hybrids show usually hybrid vigor (mutual compensation of deficits) and are generally superior in a variety of behavioral tasks [Owen et al., 1997; Lipp and Wolfer, 2003]. In fact, the Banbury Conference in 1997 recommended the use of $\mathrm{F} 1$ hybrids between common inbred strains for neurobehavioral assessment because their genetic background is likely to buffer strain-specific peculiarities [Silva et al., 1997]. However, the literature is abundant with studying AHN in C57BL/6 only, while rare studies using 
F1 hybrids have shown substantial differences between inbred and hybrid (or wild) mice [Clark et al., 2009; Klaus et al., 2012]. A study using 52 recombinant mouse strains showed extreme genetic variability and identified 190 candidate genes playing a role in the control of adult neurogenesis [Kempermann et al., 2006]. On the other hand, many studies using transgenic mouse models to manipulate $\mathrm{AHN}$ use mice from poorly controlled mixed genetic backgrounds containing strains with defects of the nervous system and behavioral impairments (129/SvEv) [Sahay et al., 2011].

\section{Sensitivity to Drugs, Hormones, and Stress}

Due to the particular location of the stem cells in the SGZ [Paredes et al., 2016], up- or downregulation of adult neurogenesis is sensitive to chemical and hormonal signals carried in the blood and in the cerebrospinal fluid from nearby circumventricular organs. This makes it difficult to recognize whether such regulation depends on intrahippocampal signals (putatively originating from cognitive processing) or physiological signals, such as generated by wheel-running, or even by interaction between different sources. Various forms of experimentally induced stress in rodents (e.g. sleep deprivation or social defeat) have been shown to suppress cell proliferation in the SGZ, the changes in AHN being investigated to study associated changes in learning behavior or assessing effects of drugs known for ameliorating depression in humans. Yet using stress as an experimental tool may add a serious source of confound, particularly in mice since it is known to trigger epigenetic changes in the response of glucocorticoid and mineralocorticoid receptors in the hippocampus [Weaver et al., 2004]. Moreover, in other brain regions it can concomitantly induce long-lasting up- or downregulation of many promoter loci controlling expression of CNS-specific genes known as epigenetic tags. For example, social defeat stress in male mice showed 1,285 upregulated and 799 downregulated genes in the nucleus accumbens alone, but the changes were observed only in about $50 \%$ of stresssensitive mice [Wilkinson et al., 2009].

The effects of potentially bimodal stress responses in an inbred strain on survival and functionality of newly generated neurons are difficult to anticipate, particularly since epigenetic changes in the dentate gyrus of mice are also observed after seemingly harmless perturbations such as exposure to novelty [Chandramohan et al., 2007; for a review see Stankiewicz et al., 2013]. Subtle stressors for rodents are also behavioral apparatus such as illuminated open fields and test chambers smelling of cleaning alcohol, specifically experimenters [Sorge et al., 2014], which most likely account in part for irreproducible behavioral results across laboratories [Crabbe et al., 1999; Chesler et al., 2002]. At least in mice, prolonged handling before experimentation does not remedy the problem [Longordo et al., 2011]. Thus, experimental manipulations aimed at analyzing the interaction between stress, $\mathrm{AHN}$, and behavioral readouts mix differential stressors with differential epigenetic consequences as long as mice are handled by experimenters and face unfamiliar test situations.

Toxicity and Side Effects of Substances Assessing and Manipulating AHN

BrdU as a mitotic marker can have (strain-specific) toxicity on neural stem cells [Taupin, 2007], and is more prone to be incorporated by replication errors [Duque and Rakic, 2011]. Likewise, other organotypic stem cells in the body might by afflicted by BrdU, causing feedback to the hippocampus, which harbors a large amount of receptors for signals from the immune system [Lathe, 2001]. These signals may interfere not only with stem cell proliferation, but also with learning and memory, e.g. as shown for the Toll-like receptor [Okun et al., 2011]. Thus, BrdU might be used for tracking the fate of newly born neurons but should be avoided in studies aimed at showing behavioral readouts. Nonetheless, a huge majority of studies continues to use it, even though better and nontoxic proliferation markers are available. More subtle effects on neural stem cells may arise from drugs such as tamoxifen used to activate genes in conditional mutant mice [Chen et al., 2013] or from transgenic insertion of a tetracycline transactivator permitting activation of CNSspecific genes by means of ingesting tetracycline or doxycycline [Han et al., 2012].

\section{Domestication}

There is clear evidence that wheel-running in wild mice species do not have the stimulatory effect as commonly observed in mouse studies. Wild wood mice (Apodemus flavicollis) patrol very large territories but show no boost in AHN after wheel-running [Hauser et al., 2009]. Similar observations were made in laboratorybred wild Mus musculus [Klaus and Amrein, 2012; Klaus et al., 2012; Schaefers, 2013], and wild Norway rats, which supposedly roam more, fall into the range of laboratory rat strains [Epp et al., 2009]. Likewise, studies of Siberian foxes indicated higher AHN in tame individuals [Huang et al., 2015]. Hence, domestication in mice and rats may have expanded considerably the spectrum of physiological factors regulating adult neurogenesis; however, this 
point is rarely considered [Kempermann, 2015]. Finally, the observation that proliferation levels of AHN in semidomesticated adult minks (1.5 years old) appear to correlate positively with stereotypic behavior [Malmkvist et al., 2012] presents another conceptual challenge for linking putative human hippocampal functions to AHN.

\section{Translational Problems}

\section{From Man to Mouse and Vice Versa}

A core assumption in translational research holds that observations in standard laboratory animals (mice and rats) can be extrapolated to humans and vice versa. While hippocampal neurophysiology and cellular features are indeed largely comparable, this is only partially true for connectivity, and rarely the case when behavior is included. Hippocampal functions have been tuned by evolution to provide optimal adaptation to the ecological niche of a species, and these niches are radically different for rodents and humans. Hippocampal malfunction in humans affects primarily memory, while rodents show multiple deficits in spatial and reversal learning as well as impairments in species-typical behaviors such as nest-building and the ability to clean out tubes filled with pebbles or food morsels [Deacon et al., 2002]. Hence, using mice to explain human hippocampal functions requires an understanding of what rodents actually use their hippocampus for during daily life in their habitual environment [Lipp and Wolfer, 2013].

\section{Are Actual Behavioral Tests Ecologically Relevant for Rodents?}

To illustrate this point, we will focus on pattern separation. The term denotes the ability to store and handle subtly different complex memories. The idea became a focus in AHN research because computational modeling showed that changing the excitability of relatively few dispersed granule cells could establish new input channels into the hippocampal subfields [Yassa and Stark, 2011]. The model provided an explanation for the vexing problem of how few newly generated cells in the dentate gyrus could have functional relevance, while partial removal of the hippocampus or a $25 \%$ reduction of the number of pyramidal cells by lesions did not affect water maze learning [Mohajeri et al., 2003].

The principle is illustrated by a frequently cited study by Sahay et al. [2011]. The authors used mice with transgenic control of survival of newly generated granule cells and tested various batches of manipulated and control

Adult Neurogenesis in Mammals:

Variations and Confusions mice in a battery of tasks. Mice with more juvenile neurons were indistinguishable in a battery of classic tests thought to measure hippocampal functions. Another mouse sample was tested in so-called 'contextual fear discrimination learning'. They were first shocked in one chamber with $0.75 \mathrm{~mA}$ (causing vigorous jumping and squealing) and were then placed the following day either into the same chamber in which they had received shocks (A) or in a chamber of the same type but marked by a few different cues (B). The behavioral readout of such tests is the ratio of immobility responses (freezing) as compared to phases when the animal is moving for escape. In chamber $\mathrm{A}$, mice continued to receive shocks at the end of the observation period, but not in chamber B. Initially both groups froze equally in either box (generalization), but gradually mice with more juvenile neurons $(\mathrm{n}=11)$ froze moderately less in box B than controls $(n=9)$; significant differences emerged at days 5 and 6 .

Yet, survival of a mouse in its natural environment depends on very fast decisions. It is difficult to see how such slowly developing fear-related discrimination learning could provide an evolutionary advantage for this species. Likewise, the ecological advantage of having proliferative processes in the dentate gyrus supporting such learning remains obscure. Nonetheless, the discrete behavioral result was taken as strong evidence for a selective effect of juvenile neurons on pattern discrimination. Confounding effects of repeated stress were not discussed, even though the same laboratory had reported earlier that heavy stress in mice entailed epigenetic changes in some 2,000 CNS genes outside the hippocampus.

\section{Are Ethology-Based Approaches Better?}

There are some recent reports indicating a recognizable correlation between individual levels of neurogenesis and spontaneous behavior, thus being more ethological and avoiding the problem of forcing the animals into short-lasting behavioral tests confounded by human handling and anxiety in test situations. For example, Freund et al. [2013, 2015] presented data showing that the emergence of individuality in exploratory roaming of mice kept in large enclosures correlated positively with proliferation levels, and negatively in mice prone to exploratory behavior independent of interaction with conspecifics.

This corresponds to the findings of van Dijk et al. [2016b] who conducted a well-designed study with inbred female mice of the strain DBA/2. A total of 106 mice obtained at exactly the same age served to assess spontaneous behavior and complex learning in automated home cages with four learning corners each (IntelliCages ${ }^{\circledR}$ ). 
They compared two age classes (2-month-old vs. 5 -month-old animals) for learning simple spatial and progressively more complex tasks including spatial rule learning and discount-delay behavior (suppressing a spontaneous behavior for a quick water reward in favor of a better sweet reward after some waiting), collecting a total of more than 1,500 behavioral readouts during a test period of 30 days. Using a Bayesian approach, they reduced false-positive correlations with proliferation rates, with surprising results. For one, there was no difference in newly generated neurons in mice having spent the same time in IntelliCages but without any learning - indicating that mental load in form of complex learning did not increase hippocampal neurogenesis. The other intriguing observation was that the number of newly generated cells did not correlate with any learning scores, but only negatively with 'exploratory' behavior during the first day in the IntelliCages. This was observed only in the older group (being in the tapering off phase of proliferation), indicating that individuals with the highest proliferation rate were visiting the learning corners least. This might imply increased caution of adult mice with high proliferation levels in novel environments.

However, other explanations are possible if the older mice would have paid more attention to novel cage mates at the expense of climbing into learning corners. Future studies must address this issue, but at present it fits well to theories assuming that variations in levels of AHN predispose individuals of a given species to different levels of exploring and adapting to new environments within the natural lifespan. The strong correlations between propensity for sucrose preference in the home cage and AHN in rats [Hu et al., 2016] points in the same direction, as they were observed in both treated and control rats. Obviously, ethological observational approaches are not superior per se, but they avoid the notorious confounds in

Fig. 4. Relating adult neurogenesis with behavior as based on group comparisons is prone to interpretation errors. a Significant group difference in the volume of the molecular in hippocampal region CA3/CA4 (regio inferior) observed in mouse strains $\mathrm{C} 3 \mathrm{H}$ and DBA/2. b Significant strain difference in two-way avoidance learning. c Significant strain difference in the extent of infrapyramidal mossy fiber projections (IIP-MF). d Correlation between individual values and two-way avoidance learning in an F2-cross between the strains reveals that volume variations of the molecular layer are unrelated to avoidance learning. e Significant correlation between the extent of the IIP-MF projection and avoidance learning indicates that a factor associated with this projection must exert a causal effect on avoidance learning. Modified from Lipp et al. behavioral testing of mice, thus increasing the chance for observing reproducible correlations.

A last argument for paying more attention to ethological factors comes from an extensive study in conventional knockout mice lacking adult neurogenesis in both SVZ and SGZ [Jaholkowski et al., 2009]. These mice compensated the lack of AHN remarkably well when tested in a large battery of learning and memory tasks aimed at revealing hippocampal malfunction. On the other hand, they were impaired in olfactory functions, and showed significant deficits in species-typical behaviors such as food burrowing and nest building [Jednyak et al., 2012], corresponding to hippocampal lesion effects in mice [Deacon et al., 2002].

\section{Interpreting Data}

\section{Inferential Conclusions}

The most common form of data presentation in the field of behavioral AHN shows that a given treatment or genetic differences result in group differences of both cell counts (endophenotype) and behavioral readouts. The implicit assumption is that parallel changes in the endophenotype and the behavioral readout indicate a causal effect of the experimentally varied cell counts on the behavioral readout. This (widely occurring) logical error in neurobehavioral studies has been criticized repeatedly [Lazic, 2010, 2012a; Lazic et al., 2014], yet without much resonance. The latter study checked more than $900 \mathrm{pa}-$ pers claiming an effect of AHN on behavioral measures, but found only 11 papers reporting a correlation between natural or experimentally induced individual levels of AHN and the behavioral scores. A meta-analysis revealed that the contribution of individual variability to the behavior scores was statistically negligible and that major

[1989].f Scheme indicating false conclusions by comparing group differences without knowledge of their data structure. g Statistical mediation analysis [Cohen et al., 2003] tries to recognize how much of the variability in the behavioral outcome can be attributed to the variations in cell numbers. In a simplified way, this can be checked by computing correlations and presenting scatterplots for the two variables in both treatment and control groups. If the scores correlate to some extent, inferring (yet not proving) causality is justified. If there are no correlations, there must be other factors than cell numbers affecting the behavior through other causal chains. Thus, reports showing no graphs of covariation between cell numbers and behavior scores are inconclusive. Modified from Lazic et al. [2014].

(For figure see next page.) 


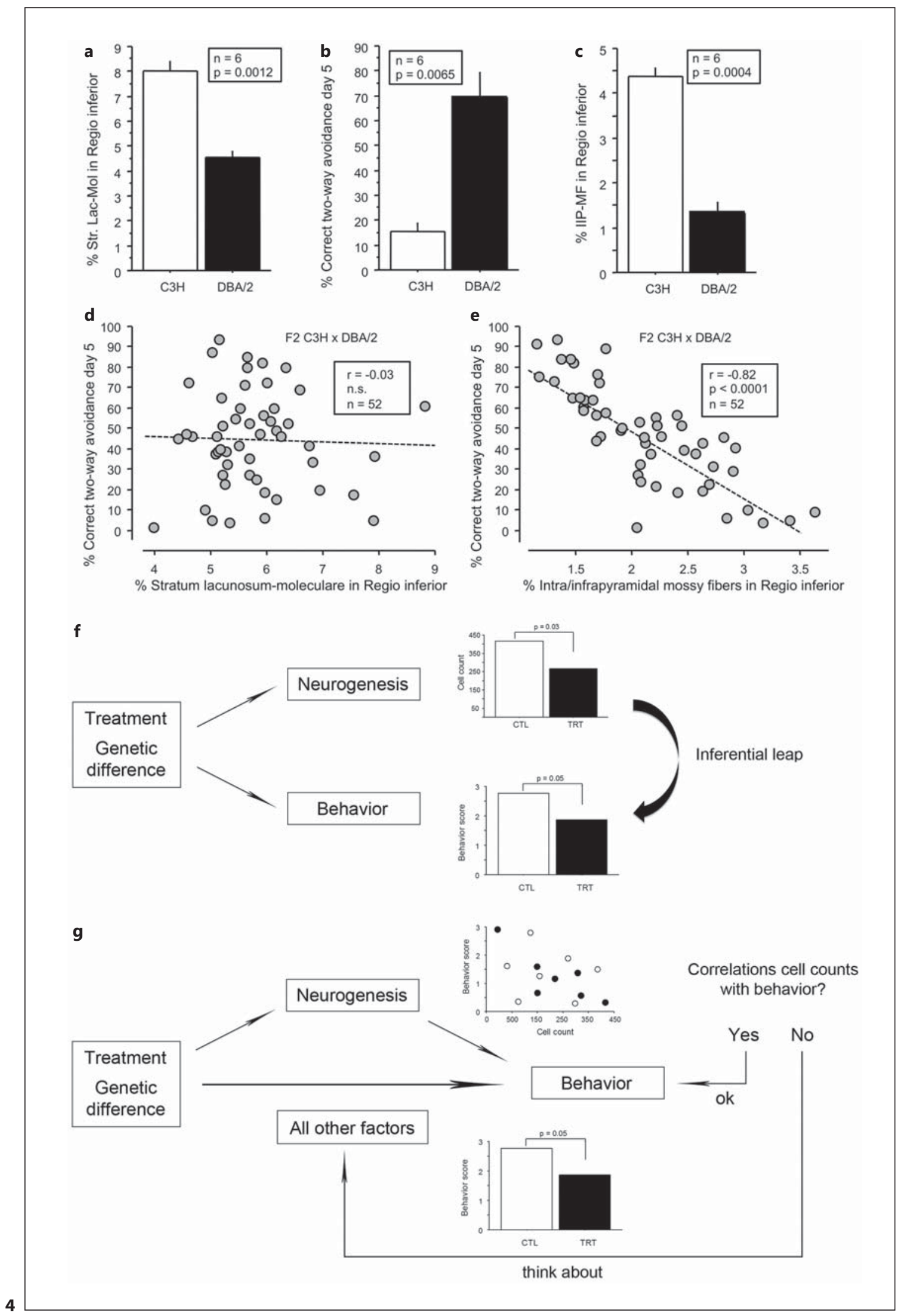


effects on behavior had to be attributed to other factors than cell counts.

The argument is shown in more detail in figure 4 . The first part deals with the risk of accepting spurious brainbehavior associations based on group differences in unrelated samples of animals, clearly the weakest method for dissecting brain-behavior relationships. This approach is most frequently used by testing batches of animals known for increased or decreased proliferation, yet without actually analyzing cell numbers in the dentate gyrus of the tested mice [Sahay et al., 2011]. The covariance between individual cell numbers and behavioral scores is not known but simply inferred.

To demonstrate the fallacy of such assumptions, we used our own data showing that the mouse strains $\mathrm{C} 3 \mathrm{H}$ and $\mathrm{DBA} / 2$ differ significantly in avoidance learning (fig. 4b). At the time of the study, we intended to show that this difference was related to the volume of synaptic fields in the CA3/CA4 region [Lipp et al., 1989]. Indeed, the poorly performing strain $\mathrm{C} 3 \mathrm{H}$ showed both significantly larger molecular layers (fig. 4a) and more mossy fiber terminals along the basal dendrites of pyramidal cells in CA3/ CA4, the infrapyramidal projection (fig. 4c). However, the structural and behavioral strain differences might be based on numerous factors unrelated to each other, such as body weight or hormonal status, and claiming a functional relation between hippocampal synaptic fields and behavior would represent a massive inferential leap not justified by the data. We then randomized noninvasively genetic factors affecting the size of the synaptic fields in CA3/CA4 simply by crossing the two strains and creating a F2 generation showing phenotypic variability of synaptic fields and avoidance learning. Figure $4 \mathrm{~d}$ shows that variation in the size of the molecular layer was now largely uncorrelated with avoidance learning scores, indicating that the initially observed link was spurious. On the contrary, there was a strong and significant negative correlation between the volume of the IIP-MF and avoidance learning. Later studies showed that the extent of the IIP-MF correlated with a variety of hippocampus-dependent behaviors as well as with behaviors not suspected of being hippocampus dependent [Lipp et al., 1989; Lipp and Wolfer, 1995].

\section{Hidden Information in Within-Group Variation of Data Points}

In studies measuring neuronal numbers and behavior in the same animal, there is no need to create artificial variation because substantial within-group variation in both variables can provide valuable information if the relations are presented at least as scatter plots. In doing so, one can easily identify whether there are correlations between cell counts and behavior, either significant or at least as trend. But a total lack of within-group correlations is suspicious for spurious relations (fig. $4 \mathrm{f}$ ) and the results must be considered as questionable. The presence of significant within-group correlations or at least trends (fig. $4 \mathrm{~g}$ ) indicates the possibility of a more causal relationship (without proving it), and papers showing them deserve more credit for their conclusions. Such inspection does not require large sample sizes. In a recent study, the number of BrdUpositive neurons was reduced by retinoic acid, followed by assessment of water maze learning and sucrose preference [Hu et al., 2016]. The data revealed that the proliferation rate appeared to be strongly correlated with individual sucrose preference within both control and treated rats, even though it included 6 rats per condition only. The lowest correlation coefficient was $r=0.79$ and the best was $r=$ 0.98 , the distribution of data points not being skewed. One may also note that such correlations were observed during spontaneous behavior in the home cage but not in the water maze. Another paper presented an analysis of sex differences in rats subjected to variants of radial maze learning thought to reveal behaviorally neurophysiological pattern separation in the hippocampus, without attempts to change potential levels of AHN experimentally [Yagi et al., 2016]. In contrast to earlier reports investigating $A H N$ and learning behavior [e.g. Sahay et al., 2011], they analyzed the cases of errors carefully, attributing them to differential strategies of problem solving. The small sample size and distribution of data points does not allow for definite conclusions of whether the survival of newly born granule cells is really linked to the behavior scores, but any reader can quickly make his own conclusions. For further examples of correlative studies, see Freund et al. [2013] and van Dijk et al. [2016b].

Thus, as a rule of thumb, the presence or absence of scatter plots in data presentations reporting changes in both adult neurogenesis and supposedly related behavior allows classifying publications as interesting and trustworthy, or, respectively, as inconclusive, thus greatly reducing the amount of papers deserving in-depth reading.

\section{Conceptual Problems}

\section{Research Findings in AHN and Their Perception by} the Public

An important mechanism driving research directions and interpretation of data in AHN is the role of the media. Widespread publicity attracts more research groups, and 
increases the pool of funding. In this respect, the seminal paper by van Praag et al. [1999] probably had the largest and longest-lasting impact. Specifically, the hypothesis that physical activity was improving cognition through stimulating AHN fit the public and clinical opinion well, even though the original report was cautious in this respect and did not provide a correlational analysis. On the other hand, follow-up papers reporting data not matching the prevailing public perception did not get much attention, even when their approaches were technically sound. For example, Japanese groups investigated the effects of differential masticatory activity on AHN in feeding soft or hardened pellets to C57BL/6 mice. Much in parallel to the first wheel-running study, they reported increased survival of BrdU-labeled neurons in the mice forced to chew more [Akazawa et al., 2013]. Moreover, the groups differed in the latest phases of water maze learning, and the hard chewers showed (shaky) superior probe trial performance exactly as in the paper by van Praag et al. [1999]. Unfortunately, neither paper showed scatter plots that would have provided clues about the behavioral relevance of the variation in BrdU-labeled neurons and the behavior scores. Nonetheless, it would be interesting to investigate whether strong chewing in elderly humans might convey the same mental benefits as other forms of more demanding physical exercise [Chen et al., 2015].

\section{More Is Better or Less Is More?}

The dominant belief in the field and in public opinion is that $\mathrm{AHN}$ is a process supporting cognition, memory, and emotional stability because it occurs in the hippocampus - a structure known to mediate cognition, memory, and emotionality. The circularity of the argument is rarely questioned. As proliferation seems to undergo an ageing process associated with progressive decline of memory capacities, stimulating AHN ought to improve cognition in the elderly, protect mental functions in the demented, and help in counteracting depressive states. This somewhat simplistic view has generated a plethora of behavioral AHN papers and corresponding subfields. Even though their results have been inconsistent, the acceptance of the 'more-is-better' concept has prevailed.

Pending confirmation, the experimentally backed recent emergence of a 'less-is-more' concept is clearly undermining the foundation for clinical prospects along the conventional route. For example, risking amnesia by stimulating AHN no longer seems attractive for the elderly. On the other hand, it has led to new approaches in the pathogenesis of schizophrenia by considering pro-

Adult Neurogenesis in Mammals:

Variations and Confusions tracted proliferation of granule cells in the human dentate gyrus as a pathological trait [Walton et al., 2012]. The concept is also compatible with views relating the time course of temporal decline in AHN to the emergence or change of habits during the life history of a given species [Amrein and Lipp, 2009], and it integrates data from different species. Finally, the finding that increasing AHN experimentally may induce forgetting might partly explain so-called 'paradoxical findings' [Ehninger and Kempermann, 2006; Saxe et al., 2007; Schoenfeld and Gould, 2013]. Hopefully, the 'less-is-more' concept will lead to studies controlling age-related dynamics of AHN in the own experimental animals as an integral part of hypothesis and research plan.

\section{Summary and Prospectus}

(i) Adult neurogenesis and its role in brain repair and neural regeneration are far from being clear. Although the brains of different animal groups (mammalian and nonmammalian) harbor active neuronal progenitors that are able to produce new neurons throughout life and which can be stimulated to contribute to neuronal repair, differences between species are apparent with regard to the extent and efficiency of repair in different locations and injury contexts. Interspecies comparisons are needed to recognize divergent pathways affecting adult neurogenesis positively or negatively.

(ii) A comparative view of adult neurogenesis in the SGZ indicates that its occurrence is highly variable, species specific, without recognizable common function up to now, and sometimes even lacking. Thus, different species may have different needs for protracted adult neurogenesis, if any. Similar markers of developmental stages of juvenile neurons appear to occur in all mammals, but their temporal correlations and expression relative to proliferating cells can vary enormously. Some of them, especially DCX, can be expressed in adult, non-newly generated cell populations, marking sites of neuronal plasticity.

(iii) A common feature of hippocampal neurogenesis is downregulation in juvenile and young-adult ages (in rats and mice between 1.5 and 4 months). Reportedly, similar turnover rates for adult humans and mice are based on a calculation error. The turnover rate in older mice is 10-20 times higher than in humans.

(iv) To understand the effects of adult neurogenesis, the lifetime course of late maturational processes in the mammalian brain such as gliogenesis, dendritogenesis, myelination, axonal sprouting and rearrangement, and 
other forms of neuronal plasticity should be known better. Yet lifetime studies in experimental animals are mostly lacking.

(v) The analysis of the behavioral functions of AHN suffers from several biological confounds or neglects. Prominent is the rapid downregulation of AHN, which can bias the effects of manipulations when they fall into time windows during which rapid change in cell numbers occurs. Most studies use only one inbred strain (C57BL6), but should be done in $\mathrm{F} 1$ hybrids between well-characterized strains for buffering strain-specific genetic variation. Critical results should be checked in nondomesticated mice.

(vi) Stress-related hormones can exert a massive impact on AHN. However, sensitivity to stressors is individually different even within inbred strains, due to longlasting epigenetic up- or downregulation of promoter loci outside the hippocampus, even by minor stressors. The safest way to reduce variability in behavioral studies is by keeping experimenters away from the animals, and by using noninvasive proliferation markers.

(vii) Novel behavioral tests such as pattern separation aiming at demonstrating a specific role of newly generated neurons appear irrelevant for the ecological situation of mice and rats and are thus likely to generate more unequivocal data.

(viii) Promising approaches for identifying the behavioral role of AHN in rodents should focus on ethologybased behavioral assessment without interference by experimenter and potentially anxiogenic test set-ups. Discovery of relations is now possible by automated behavioral observation and cognitive testing.

(ix) The statistical interpretation of data in behavioral research in AHN is biased by unjustified inferential leaps. In the worst case, causation is inferred by observing parallel changes in functional readouts after a treatment increasing or decreasing cell proliferation in different sam- ples. Most studies in which cell counts and behavioral readouts were done in the same animals do not report covariance between the scores although it could be done easily.

(x) Further biases in interpretation arise from public perception of animal studies suggesting positive perspectives for improving mental health in ageing or depressed people, mostly by a 'more-is-better' approach. The emergence of a 'less-is-more' approach can explain paradoxical results and fits well with developmental and comparative data.

In conclusion, we believe that the field of adult neurogenesis has a solid basis for understanding the molecular and developmental mechanisms regulating neurogenesis. The functional consequences of adult neurogenesis for both regeneration and behavioral/cognitive effects will remain elusive and contradictory unless investigators are willing to make more efforts to analyze their material for processes accompanying induced or natural changes in cell proliferation, and try to integrate reports opposing their findings instead of ignoring them. More stringent reviews and editorial requests for proper statistics justifying conclusions would be helpful. Ultimately, the field may deflate by itself when scientists realize that the main promises of AHN cannot be realized with quick studies any longer. The curve of publications in the coming years will show whether the field of AHN is just leveling off, or whether we will see a progressive decline. Given the huge financial investments by governments and industry, one may hope for a continuation at least avoiding the pitfalls outlined here, ideally with novel approaches and ideas.

\section{Acknowledgments}

We appreciate the permission of Irmgard Amrein and Ottavia Palazzo in providing unpublished graphic material and the administrative help of Irina Lipp.
References
Akazawa Y, Kitamura T, Fujihara Y, Yoshimura Y, Mitome M, Hasegawa T (2013): Forced mastication increases survival of adult neural stem cells in the hippocampal dentate gyrus. Int J Mol Med 31:307-314.

Akers KG, Martinez-Canabal A, Restivo L, Yiu AP, De Cristofaro A, Hsiang HL, Wheeler AL, Guskjolen A, Niibori Y, Shoji H, Ohira K, Richards BA, Miyakawa T, Josselyn SA, Frankland PW (2014): Hippocampal neurogenesis regulates forgetting during adulthood and infancy. Science 344:598-602.
Alunni A, Bally-Cuif L (2016): A comparative view of regenerative neurogenesis in vertebrates. Development 143:741-753.

Amrein I (2015): Adult hippocampal neurogenesis in natural populations of mammals. Cold Spring Harb Perspect Biol 7:pii:a021295.

Amrein I, Dechmann DK, Winter Y, Lipp HP (2007): Absent or low rate of adult neurogenesis in the hippocampus of bats (Chiroptera). PLoS One 2:e455. 
Amrein I, Isler K, Lipp HP (2011): Comparing adult hippocampal neurogenesis in mammalian species and orders: influence of chronological age and life history stage. Eur J Neurosci 34:978-987.

Amrein I, Lipp HP (2009): Adult hippocampal neurogenesis of mammals: evolution and life history. Biol Lett 5:141-144.

Amrein I, Slomianka L (2010): A morphologically distinct granule cell type in the dentate gyrus of the red fox correlates with adult hippocampal neurogenesis. Brain Res 1328:12-24.

Amrein I, Slomianka L, Poletaeva, II, Bologova NV, Lipp HP (2004): Marked species and agedependent differences in cell proliferation and neurogenesis in the hippocampus of wild-living rodents. Hippocampus 14:10001010.

Bartkowska K, Djavadian RL, Taylor JR, Turlejski K (2008): Generation recruitment and death of brain cells throughout the life cycle of Sorex shrews (Lipotyphla). Eur J Neurosci 27:17101721.

Ben Abdallah NM, Slomianka L, Vyssotski AL, Lipp HP (2010): Early age-related changes in adult hippocampal neurogenesis in C57 mice. Neurobiol Aging 31:151-161.

Bergmann O, Spalding KL, Frisen J (2015): Adult neurogenesis in humans. Cold Spring Harb Perspect Biol 7:a018994.

Bonfanti L (2011): From hydra regeneration to human brain structural plasticity: a long trip through narrowing roads. Scientific World J 11:1270-1299.

Bonfanti L (2016): Adult neurogenesis 50 years later: limits and opportunities in mammals. Front Neurosci 10:44.

Bonfanti L, Nacher J (2012): New scenarios for neuronal structural plasticity in non-neurogenic brain parenchyma: the case of cortical layer II immature neurons. Prog Neurobiol 98:1-15.

Bonfanti L, Peretto P (2007): Radial glial origin of the adult neural stem cells in the subventricular zone. Prog Neurobiol 83:24-36.

Bonfanti L, Peretto P (2011): Adult neurogenesis in mammals - a theme with many variations. Eur J Neurosci 34:930-950.

Brown JP, Couillard-Despres S, Cooper-Kuhn CM, Winkler J, Aigner L, Kuhn HG (2003): Transient expression of doublecortin during adult neurogenesis. J Comp Neurol 467:1-10.

Caroni P, Schwab ME (1993): Oligodendrocyteand myelin-associated inhibitors of neurite growth in the adult nervous system. Adv Neurol 61:175-179.

Chandramohan Y, Droste SK, Reul JM (2007): Novelty stress induces phospho-acetylation of histone $\mathrm{H} 3$ in rat dentate gyrus granule neurons through coincident signalling via the $\mathrm{N}$-methyl-D-aspartate receptor and the glucocorticoid receptor: Relevance for c-fos induction. J Neurochem 101:815-828.

Chen H, Iinuma M, Onozuka M, Kubo KY (2015): Chewing maintains hippocampus-dependent cognitive function. Int J Med Sci 12:502-509.
Chen HY, Yang YM, Han R, Noble M (2013): MEK1/2 inhibition suppresses tamoxifen toxicity on CNS glial progenitor cells. J Neurosci 33:15069-15074.

Chesler EJ, Wilson SG, Lariviere WR, RodriguezZas SL, Mogil JS (2002): Influences of laboratory environment on behavior. Nat Neurosci 5:1101-1102.

Clark PJ, Brzezinska WJ, Puchalski EK, Krone DA, Rhodes JS (2009): Functional analysis of neurovascular adaptations to exercise in the dentate gyrus of young adult mice associated with cognitive gain. Hippocampus 19:937950.

Cohen J, Cohen P, West GS, Aiken LS (2003): Applied Multiple Regression/Correlation Analysis for the Behavioral Sciences, ed 3. Mahwah, Erlbaum.

Couillard-Despres S (2013): Hippocampal neurogenesis and ageing. Curr Top Behav Neurosci 15:343-355.

Couillard-Despres S, Iglseder B, Aigner L (2011): Neurogenesis, cellular plasticity and cognition: the impact of stem cells in the adult and aging brain - a mini-review. Gerontology 57 : 559-564.

Crabbe JC, Wahlsten D, Dudek BC (1999): Genetics of mouse behavior: interactions with laboratory environment. Science 284:1670-1672.

Deacon RM, Croucher A, Rawlins JN (2002): Hippocampal cytotoxic lesion effects on species-typical behaviours in mice. Behav Brain Res 132:203-213.

Duque A, Rakic P (2011): Different effects of bromodeoxyuridine and $[3 \mathrm{H}]$ thymidine incorporation into DNA on cell proliferation, position, and fate. J Neurosci 31:15205-15217.

Ehninger D, Kempermann G (2006): Paradoxical effects of learning the Morris water maze on adult hippocampal neurogenesis in mice may be explained by a combination of stress and physical activity. Genes Brain Behav 5:29-39.

Epp JR, Barker JM, Galea LA (2009): Running wild: neurogenesis in the hippocampus across the lifespan in wild and laboratory-bred Norway rats. Hippocampus 19:1040-1049.

Epp JR, Chow C, Galea LA (2013): Hippocampusdependent learning influences hippocampal neurogenesis. Front Neurosci 7:57.

Fawcett JW, Schwab ME, Montani L, Brazda N, Müller HW (2012): Defeating inhibition of regeneration by scar and myelin components. Handb Clin Neurol 109:503-522.

Feliciano DM, Bordey A, Bonfanti L (2015): Noncanonical sites of adult neurogenesis in the mammalian brain. Cold Spring Harb Perspect Biol 7:a018846.

Freund J, Brandmaier AM, Lewejohann L, Kirste I, Kritzler M, Krüger A, Sachser N, Lindenberger U, Kempermann G (2013): Emergence of individuality in genetically identical mice. Science 340:756-759.
Freund J, Brandmaier AM, Lewejohann L, Kirste I, Kritzler M, Krüger A, Sachser N, Lindenberger U, Kempermann G (2015): Association between exploratory activity and social individuality in genetically identical mice living in the same enriched environment. Neuroscience 309:140-152.

Gil-Mohapel J, Brocardo PS, Choquette W, Gothard R, Simpson JM, Christie BR (2013): Hippocampal neurogenesis levels predict watermaze search strategies in the aging brain. PLoS One 8:e75125.

Gomez-Climent MA, Castillo-Gomez E, Varea E, Guirado R, Blasco-Ibanez JM, Crespo C, Martinez-Guijarro FJ, Nacher J (2008): A population of prenatally generated cells in the rat paleocortex maintains an immature neuronal phenotype into adulthood. Cereb Cortex 18: 2229-2240.

Gould E, Beylin A, Tanapat P, Reeves A, Shors TJ (1999): Learning enhances adult neurogenesis in the hippocampal formation. Nat Neurosci 2:260-265.

Han HJ, Allen CC, Buchovecky CM, Yetman MJ, Born HA, Marin MA, Rodgers SP, Song BJ, Lu HC, Justice MJ, Probst FJ, Jankowsky JL (2012): Strain background influences neurotoxicity and behavioral abnormalities in mice expressing the tetracycline transactivator. J Neurosci 32:10574-10586.

Hauser T, Klaus F, Lipp HP, Amrein I (2009): No effect of running and laboratory housing on adult hippocampal neurogenesis in wild caught long-tailed wood mouse. BMC Neurosci 10:43.

Hu P, Wang Y, Liu J, Meng FT, Qi XR, Chen L, van Dam AM, Joels M, Lucassen PJ, Zhou JN (2016): Chronic retinoic acid treatment suppresses adult hippocampal neurogenesis, in close correlation with depressive-like behavior. Hippocampus, Epub ahead of print.

Huang S, Slomianka L, Farmer AJ, Kharlamova AV, Gulevich RG, Herbeck YE, Trut LN, Wolfer DP, Amrein I (2015): Selection for tameness, a key behavioral trait of domestication, increases adult hippocampal neurogenesis in foxes. Hippocampus 25:963-975.

Jabes A, Lavenex PB, Amaral DG, Lavenex P (2010): Quantitative analysis of postnatal neurogenesis and neuron number in the macaque monkey dentate gyrus. Eur J Neurosci 31:273-285.

Jaholkowski P, Kiryk A, Jedynak P, Ben Abdallah NM, Knapska E, Kowalczyk A, Piechal A, Blecharz-Klin K, Figiel I, Lioudyno V, WidyTyszkiewicz E, Wilczynski GM, Lipp HP, Kaczmarek L, Filipkowski RK (2009): New hippocampal neurons are not obligatory for memory formation; cyclin D2 knockout mice with no adult brain neurogenesis show learning. Learn Mem 16:439-451.

Jedynak P, Jaholkowski P, Wozniak G, Sandi C, Kaczmarek L, Filipkowski RK (2012): Lack of cyclin D2 impairing adult brain neurogenesis alters hippocampal-dependent behavioral tasks without reducing learning ability. Behav Brain Res 227:159-166.
Adult Neurogenesis in Mammals: Variations and Confusions
Brain Behav Evol 2016;87:205-221 
Kempermann G (2015): Adult neurogenesis: an evolutionary perspective. Cold Spring Harb Perspect Biol 8:a018986.

Kempermann G, Chesler EJ, Lu L, Williams RW, Gage FH (2006): Natural variation and genetic covariance in adult hippocampal neurogenesis. Proc Natl Acad Sci USA 103:780785.

Klaus F, Amrein I (2012): Running in laboratory and wild rodents: differences in context sensitivity and plasticity of hippocampal neurogenesis. Behav Brain Res 227:363-370.

Klaus F, Hauser T, Lindholm AK, Cameron HA, Slomianka L, Lipp HP, Amrein I (2012): Different regulation of adult hippocampal neurogenesis in Western house mice (Mus musculus domesticus) and C57BL/6 mice. Behav Brain Res 227:340-347.

Klempin F, Kronenberg G, Cheung G, Kettenmann H, Kempermann G (2011): Properties of doublecortin-(DCX)-expressing cells in the piriform cortex compared to the neurogenic dentate gyrus of adult mice. PLoS One 6:e25760.

Knoth R, Singec I, Ditter M, Pantazis G, Capetian P, Meyer RP, Horvat V, Volk B, Kempermann $G$ (2010): Murine features of neurogenesis in the human hippocampus across the lifespan from 0 to 100 years. PLoS One 5:e8809.

Konishi Y, Matsu-Ura T, Mikoshiba K, Tamura T (2001): Stimulation of gene expression of NeuroD-related factor in the mouse brain following pentylenetetrazol-induced seizures. Brain Res Mol Brain Res 97:129-136.

Kornack DR, Rakic P (1999): Continuation of neurogenesis in the hippocampus of the adult macaque monkey. Proc Natl Acad Sci USA 96:5768-5773.

Kriegstein A, Alvarez-Buylla A (2009): The glial nature of embryonic and adult neural stem cells. Annu Rev Neurosci 32:149-184.

Lathe R (2001): Hormones and the hippocampus. J Endocrinol 169:205-231.

Lazic SE (2010): Relating hippocampal neurogenesis to behavior: the dangers of ignoring confounding variables. Neurobiol Aging 31: 2169-2171; discussion 2172-2175.

Lazic SE (2012a): Using causal models to distinguish between neurogenesis-dependent and -independent effects on behaviour. J R Soc Interface 9:907-917.

Lazic SE (2012b): Modeling hippocampal neurogenesis across the lifespan in seven species. Neurobiol Aging 33:1664-1671.

Lazic SE, Fuss J, Gass P (2014): Quantifying the behavioural relevance of hippocampal neurogenesis. PLoS One 9:e113855.

Lindvall O, Kokaia Z (2015): Neurogenesis following stroke affecting the adult brain. Cold Spring Harb Perspect Biol 7:pii:a019034.

Lipp H-P, Schwegler H, Crusio WE, Wolfer DP, Leisinger-Trigona MC, Heimrich B, Driscoll P (1989): Using genetically-defined rodent strains for the identification of hippocampal traits relevant for two-way avoidance behavior: a non-invasive approach. Experientia 45 845-859.
Lipp H-P, Wolfer DP (1995): New paths towards old dreams: microphrenology or the study of intact brains in intact worlds; in Alleva E, Fasolo A, Lipp H-P, Nadel L, Ricceri L (eds): Behavioural Brain Research in Naturalistic and Semi-Naturalistic Settings: Possibilities and Perspectives. Dordrecht, Kluwer, pp 1-39.

Lipp H-P, Wolfer DP (2003): Genetic background problems in the analysis of cognitive and neuronal changes in genetically modified mice. Clin Neurosci Res 3:221-232.

Lipp H-P, Wolfer DP (2013): Natural neurobiology and behavior of the mouse: relevance for behavioral studies in the laboratory; in Crusio WE, Sluyter F, Gerlai RT, Pietropaola S (eds): Behavioral Genetics of the Mouse. Genetics of Behavioral Phenotypes. New York, Cambridge University Press, vol 1, pp 5-16.

Longordo F, Fan J, Steimer T, Kopp C, Luthi A (2011): Do mice habituate to 'gentle handling?' A comparison of resting behavior, corticosterone levels and synaptic function in handled and undisturbed C57BL/6J mice. Sleep 34:679-681.

Luzzati F, Bonfanti L, Fasolo A, Peretto P (2009): DCX and PSA-NCAM expression identifies a population of neurons preferentially distributed in associative areas of different pallial derivatives and vertebrate species. Cereb Cortex 19:1028-1041.

Malmkvist J, Brix B, Henningsen K, Wiborg O (2012): Hippocampal neurogenesis increase with stereotypic behavior in mink (Neovison vison). Behav Brain Res 229:359-364.

Martino G, Pluchino S, Bonfanti L, Schwartz M (2011): Brain regeneration in physiology and pathology: the immune signature driving therapeutic plasticity of neural stem cells. Physiol Rev 91:1281-1304.

Mohajeri MH, Saini K, Li H, Crameri A, Lipp HP, Wolfer DP, Nitsch RM (2003): Intact spatial memory in mice with seizure-induced partial loss of hippocampal pyramidal neurons. Neurobiol Dis 12:174-181.

Morrison SJ (2014): Time to do something about reproducibility. Elife 3 DOI: 10.7554/eLife. 03981.

Nakashiba T, Cushman JD, Pelkey KA, Renaudineau S, Buhl DL, McHugh TJ, Rodriguez Barrera V, Chittajallu R, Iwamoto KS, McBain CJ, Fanselow MS, Tonegawa S (2012): Young dentate granule cells mediate pattern separation, whereas old granule cells facilitate pattern completion. Cell 149:188-201.

Nottebohm F (2004): The road we travelled: discovery, choreography, and significance of brain replaceable neurons. Ann NY Acad Sci 1016:628-658.

Okun E, Griffioen KJ, Mattson MP (2011): Tolllike receptor signaling in neural plasticity and disease. Trends Neurosci 34:269-281.
Owen EH, Logue SF, Rasmussen DL, Wehner JM (1997): Assessment of learning by the Morris water task and fear conditioning in inbred mouse strains and F1 hybrids: implications of genetic background for single gene mutations and quantitative trait loci analyses. Neuroscience 80:1087-1099.

Paredes MF, Sorrells SF, Garcia-Verdugo JM, Alvarez-Buylla A (2016): Brain size and limits to adult neurogenesis. J Comp Neurol 524:646664

Parolisi R, Peruffo A, Messina S, Panin M, Montelli S, Giurisato M, Cozzi B, Bonfanti L (2015): Forebrain neuroanatomy of the neonatal and juvenile dolphin (T. truncatus and S. coeruloalba). Front Neuroanat 9:140.

Patzke N, Spocter MA, Karlsson KAE, Bertelsen MF, Haagensen M, Chawana R, Streicher S, Kaswera C, Gilissen E, Alagaili AN, Mohammed OB, Reep RL, Bennett NC, Siegel JM, Ihunwo AO, Manger PR (2015): In contrast to many other mammals, cetaceans have relatively small hippocampi that appear to lack adult neurogenesis. Brain Struct Funct 220: 361-383.

Penz OK, Fuzik J, Kurek AB, Romanov R, Larson J, Park TJ, Harkany T, Keimpema E (2015): Protracted brain development in a rodent model of extreme longevity. Sci Rep 5:11592.

Peretto P, Bonfanti L (2014): Major unsolved points in adult neurogenesis: doors open on a translational future? Front Neurosci 8:154.

Reif A, Fritzen S, Finger M, Strobel A, Lauer M, Schmitt A, Lesch KP (2006): Neural stem cell proliferation is decreased in schizophrenia, but not in depression. Mol Psychiatry 11:514522

Sahay A, Scobie KN, Hill AS, O'Carroll CM, Kheirbek MA, Burghardt NS, Fenton AA, Dranovsky A, Hen R (2011): Increasing adult hippocampal neurogenesis is sufficient to improve pattern separation. Nature 472:466470.

Sanai N, Nguyen T, Ihrie RA, Mirzadeh Z, Tsai HH, Wong M, Gupta N, Berger MS, Huang E, Garcia-Verdugo JM, Rowitch DH, AlvarezBuylla A (2011): Corridors of migrating neurons in the human brain and their decline during infancy. Nature 478:382-386.

Saxe MD, Malleret G, Vronskaya S, Mendez I, Garcia AD, Sofroniew MV, Kandel ER, Hen R (2007): Paradoxical influence of hippocampal neurogenesis on working memory. Proc Natl Acad Sci USA 104:4642-4646.

Schaefers AT (2013): Rearing conditions and domestication background determine regulation of hippocampal cell proliferation and survival in adulthood-laboratory $\mathrm{CD} 1$ and C57Bl/6 mice versus wild house mice. Neuroscience 228:120-127.

Schoenfeld TJ, Gould E (2013): Differential effects of stress and glucocorticoids on adult neurogenesis. Curr Top Behav Neurosci 15:139_ 164 . 
Silva AJ, Simpson EM, Takahashi JS, Lipp H-P, Nakanishi S, Wehner JM, Giese KP, Tully T, Abel T, Chapman PF, Fox K, Grant SGN, Itohara S, Lathe R, Mayford M, McNamara JO, Morris RJ, Picciotto M, Roder JC, Shin H-S, Slesinger PA, Storm DR, Stryker MP, Wang Y, Wolfer DP (1997): Mutant mice and neuroscience: recommendations concerning genetic background. Banbury Conference on genetic background in mice. Neuron 19:755759.

Simic G, Kostovic I, Winblad B, Bogdanovic N (1997): Volume and number of neurons of the human hippocampal formation in normal aging and Alzheimer's disease. J Comp Neurol 379:482-494.

Siwak-Tapp CT, Head E, Muggenburg BA, Milgram NW, Cotman CW (2007): Neurogenesis decreases with age in the canine hippocampus and correlates with cognitive function. Neurobiol Learn Mem 88:249-259.

Sorge RE, Martin LJ, Isbester KA, Sotocinal SG, Rosen S, Tuttle AH, Wieskopf JS, Acland EL, Dokova A, Kadoura B, Leger P, Mapplebeck JC, McPhail M, Delaney A, Wigerblad G, Schumann AP, Quinn T, Frasnelli J, Svensson CI, Sternberg WF, Mogil JS (2014): Olfactory exposure to males, including men, causes stress and related analgesia in rodents. Nat Methods 11:629-632.

Spalding KL, Bergmann O, Alkass K, Bernard S, Salehpour M, Huttner HB, Bostrom E, Westerlund I, Vial C, Buchholz BA, Possnert G, Mash DC, Druid H, Frisen J (2013): Dynamics of hippocampal neurogenesis in adult humans. Cell 153:1219-1227.
Stankiewicz AM, Swiergiel AH, Lisowski P (2013): Epigenetics of stress adaptations in the brain. Brain Res Bull 98:76-92.

Taupin P (2007): BrdU immunohistochemistry for studying adult neurogenesis: paradigms, pitfalls, limitations, and validation. Brain Res Rev 53:198-214.

van Dijk RM, Huang SH, Slomianka L, Amrein I (2016a): Taxonomic separation of hippocampal networks: principal cell populations and adult neurogenesis. Front Neuroanat 10:22.

van Dijk RM, Lazic SE, Slomianka L, Wolfer DP, Amrein I (2016b): Large-scale phenotyping links adult hippocampal neurogenesis to the reaction to novelty. Hippocampus 26:646657.

van Praag H, Kempermann G, Gage FH (1999): Running increases cell proliferation and neurogenesis in the adult mouse dentate gyrus. Nat Neurosci 2:266-270.

Vich-Plesko M (1999): Qualitative and Quantitative Morphological Evidence for Ongoing Myelination in the Hippocampus of the Adult Mouse; MD thesis, University of Zurich, Zurich.

Walton NM, Zhou Y, Kogan JH, Shin R, Webster M, Gross AK, Heusner CL, Chen Q, Miyake S, Tajinda K, Tamura K, Miyakawa T, Matsumoto M (2012): Detection of an immature dentate gyrus feature in human schizophrenia/bipolar patients. Transl Psychiatry 2:e135.
Weaver IC, Cervoni N, Champagne FA, D’alessio AC, Sharma S, Seckl JR, Dymov S, Szyf M, Meaney MJ (2004): Epigenetic programming by maternal behavior. Nat Neurosci 7:847854 .

Weil ZM, Norman GJ, DeVries AC, Nelson RJ (2008): The injured nervous system: a Darwinian perspective. Prog Neurobiol 86:48-59.

West MJ (1993): Regionally specific loss of neurons in the aging human hippocampus. Neurobiol Aging 14:287-293.

Wilke SA, Hall BJ, Antonios JK, Denardo LA, Otto S, Yuan B, Chen F, Robbins EM, Tiglio K, Williams ME, Qiu Z, Biederer T, Ghosh A (2012): NeuroD2 regulates the development of hippocampal mossy fiber synapses. Neural Dev 7:9.

Wilkinson MB, Xiao G, Kumar A, LaPlant Q, Renthal W, Sikder D, Kodadek TJ, Nestler EJ (2009): Imipramine treatment and resiliency exhibit similar chromatin regulation in the mouse nucleus accumbens in depression models. J Neurosci 29:7820-7832.

Wolfer DP, Lipp H-P (1995): Evidence for physiological sprouting of hippocampal mossy fiber collaterals in the guinea pig during puberty and adulthood. Hippocampus 5:329-340.

Yagi S, Chow C, Lieblich SE, Galea LA (2016): Sex and strategy use matters for pattern separation, adult neurogenesis, and immediate early gene expression in the hippocampus. Hippocampus 26:87-101.

Yassa MA, Stark CE (2011): Pattern separation in the hippocampus. Trends Neurosci 34:515525 . 